\title{
Numerical Investigation of Double Corrugated Steel Plate Shear Walls
}

\author{
S.M. Ghodratian-Kashan, S. Maleki* \\ Department of Civil Engineering, Sharif University of Technology, Azadi Ave., Tehran, Iran \\ E-mail: smaleki@sharif.edu
}

Received: 23 November 2020; Accepted: 24 December 2020; Available online: 10 February 2021

\begin{abstract}
Recently, corrugated steel plate shear walls have been shown to be an efficient lateral force resisting system for building structures. Corrugated plates have higher out-of-plane stiffness and improved buckling stability in comparison with flat plates which result in improved hysteretic behavior. However, the thickness of the corrugated plates may be limited due to the cold-form process restrictions. This paper investigates the cyclic performance of double corrugated steel plate shear walls. One-story single-bay specimen was designed and modelled and parametric studies were performed. The parametric study considered the orientation of corrugated plates (horizontal or vertical), disconnection of infill plates from columns, disconnection of infill plates from each other, infill plate thickness and infill plate aspect ratio on cyclic performance of double corrugated steel plate shear walls. The present study results show that proper selection of the aforementioned parameters can lead to a desirable cyclic performance. In the end, a recommendation for calculating initial stiffness and ultimate strength of double corrugated steel plate shear walls is given.
\end{abstract}

Keywords: Steel plate shear wall; Corrugated plate; Double infill plate; Cyclic behavior; Numerical simulation.

\section{Introduction}

Steel plate shear walls (SPSWs) have been widely used as a lateral force resisting system (LFRS) in building design and retrofit. SPSWs are classified into two types, stiffened and unstiffened. The stiffened types have higher stiffness and strength and energy dissipation. However, in the stiffened SPSWs the construction is significantly costly due to thin plates welding [1]. Unstiffened SPSWs have low buckling strength and allow shear buckling and development of diagonal tension field under lateral load. The post-buckling diagonal tension strips induce large axial and flexural demands on the frame. If the frame is capacity designed for expected yield strength of infill plates, as is required by AISC provisions [2], the required column sizes can be considerable. On the other hand, in retrofit situations large demands induced from the infill plates yielding would likely require significant reinforcement of the existing columns. For reducing column demand, researchers have proposed variety of methods such as perforating the infill plate to reduce SPSW stiffness and strength [3], using low yield point steel for infill plates [4] or utilizing light gauge plate for infill plates [5]. Berman and Bruneau [5] conducted tests on three light-gauge flat and corrugated SPSWs. The corrugated panel was placed diagonally with an inclination angle of 45 degrees to the horizontal line. The results showed that corrugated specimen experienced rapid loss in strength and infill plate fractures occurred at the location of repeated local buckling.

Thin flat SPSWs experience severe pinching in their hysteresis loops due to diagonal tension field effects. To enhance the buckling load and hysteresis behavior of flat SPSWs, corrugated SPSWs were also proposed by Emami et al. [6]. They carried out laboratory tests to compare the cyclic performance of corrugated steel plate shear walls (CSPSWs) and a flat steel plate shear wall (FSPSW). The corrugated plates were laid both horizontal and vertical. It was revealed that CSPSWs show significantly less pinching in their hysteresis loops than the FSPSW due to higher out of plane stiffness and buckling strength of corrugated plates with respect to flat plates. Emami and Mofid [7] conducted numerical study on CSPSWs and confirmed the effectiveness of corrugated plates in enhancing SPSWs behavior. Farzampour et al. [8] in a numerical study compared monotonic behavior of SPSW and CSPSW with openings. Bahrebar et al. [9] performed numerical study on the cyclic behavior of the CSPSW with a square opening. Cao and Huang [10] carried out experimental and numerical study on two CSPSWs and showed that by properly designing the geometry of corrugated infill plates, the CSPSWs could avoid elastic buckling. Tong et al. [11] investigated the elastic buckling of double corrugated plate shear wall theoretically and numerically via finite element analysis. Dou et al. [12] studied the elastic shear buckling of infill panels in sinusoidally CSPSWs. Farzampour et al. [13] proposed design procedures for CSPSWs with reduced beam section. Bahrebar et al. [14] investigated the cyclic performance of perforated steel plate shear wall with curved corrugated webs. Fang et al. [15] carried out experimental study on the hysteretic behavior of semi-rigid frame with a 
corrugated plate. Bahrebar et al. [16] studied the response of low yield point steel plate shear wall with curved corrugated web plates and reduced beam sections.

The growth of SPSW structures in high-rise construction worldwide requires larger range of thicknesses for infill panels. However, the available thickness for single corrugated plates may be limited due to cold-forming process restrictions. A double corrugated SPSWs (DCSPSW) consists of two similar corrugated steel plates placed symmetrically and bolted together at contact points with uniform spacing (Figure 1). In this study, the cyclic performance of DCSPSWs is evaluated. To this end, a one-story single-bay specimen was modelled and analysed using nonlinear material and geometry options available in ABAQUS [17] software package. A parametric study was performed on the model by varying its geometry and corrugated plate properties. The parametric study considered the orientation of corrugated plates (horizontal or vertical), the effect of disconnecting the plates from the columns, the effect of disconnecting the plates from each other, corrugated plate thickness and aspect ratio. In the end, recommendations for calculating the initial stiffness and ultimate strength of DCSPSWs are given.

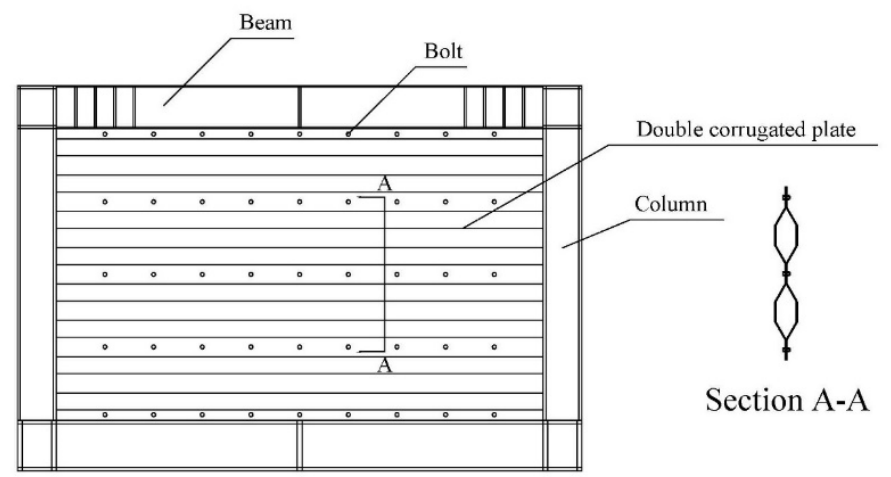

Figure 1. Double corrugated steel plate shear wall (DCSPSW)

\section{Finite element modeling}

One-story single-bay specimen with moment-resisting beam to column connections was preliminary designed according to the procedures specified in reference [1]. Specimens' dimensions and component sizes are illustrated in Figure 2. In horizontal and vertical DCSPSW specimens, corrugation fold lines are parallel to the beams and columns, respectively. The height and length of specimens are measured as $1.74 \mathrm{~m}$ and $2.7 \mathrm{~m}$, center to center of members, respectively. The model represents half-scale conventional residential building framing.

The models were developed in the finite element package ABAQUS [17]. Both material and geometrical nonlinearities were considered in the models. The fish plates connecting the infill panel to the beams and columns, were not modelled in the finite element simulation. This approximation seems to have negligible effects on the analysis results [18]. Boundary frame components, i.e. beams, columns and stiffeners and double corrugated infill panels were modelled using S4R element, a four-node doubly curved shell element. This element has six degree of freedom per node with reduced integration and finite membrane strain. Mesh size for boundary frame members is $50 \mathrm{~mm}$ and for infill plate is $25 \mathrm{~mm}$. Since the beam-to-column connections are rigid, shell elements at intersecting parts were directly connected. Bolts were not simulated directly. However, to model the effect of bolts, infill plates at the contact surfaces are directly connected (Figure 3). The double infill plates are connected to the boundary elements using "Tie" constraint command. The material for infill plate and boundary frame components were ST12 and ST37 steels according to DIN standard [19], respectively. Mechanical properties of ST12 and ST37 steel were adopted from coupon tests done by Hosseinzadeh et al. [20] and Jahanpour et al. [21], respectively and are shown in Table 1. In order to get cyclic deteriorations in the steel material strength and stiffness, "ductile damage" using stress triaxiality dependent fracture initiation criterion and fracture evolution law in the form of strain softening was accommodated in material modelling [22].

To prevent the out-of-plane displacement of the specimen, as provided by lateral supports in typical test setups, the nodes at the perimeter of the top beam-column connections panel and at the center of the top beam were restrained from translation in out-of-plane direction. The bottom flange of the bottom beam was fixed in the model similar to the boundary conditions of Emami et al. [6]. Typical finite element models for both horizontal and vertical DCSPSW specimens are shown in Figure 4. It was reported that in single corrugated SPSWs initial imperfection has no meaningful effect on the finite element results [7]. However, in this study, initial imperfection as out of plane deformation of $1 \mathrm{~mm}$ according to model eigenvalue buckling analysis was applied to the model. This was achieved by using “imperfection” command to modify the nodes coordinates. 


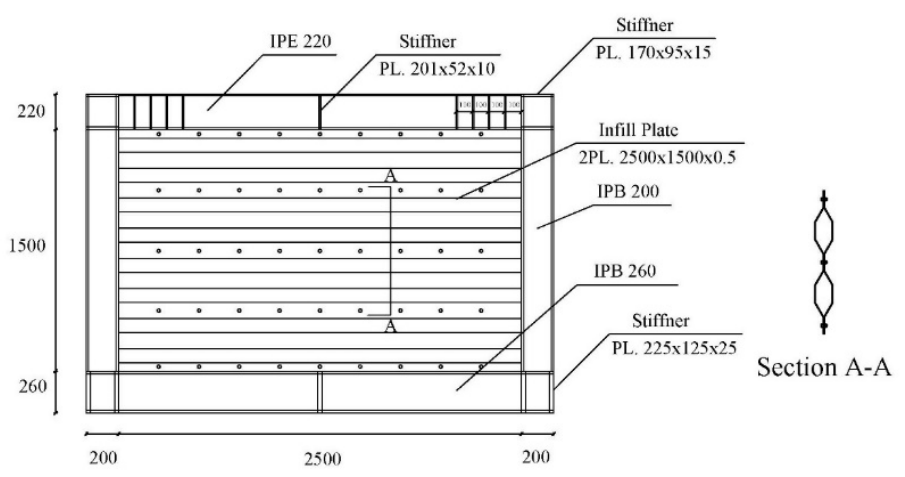

(a) Horizontal DCSPSW

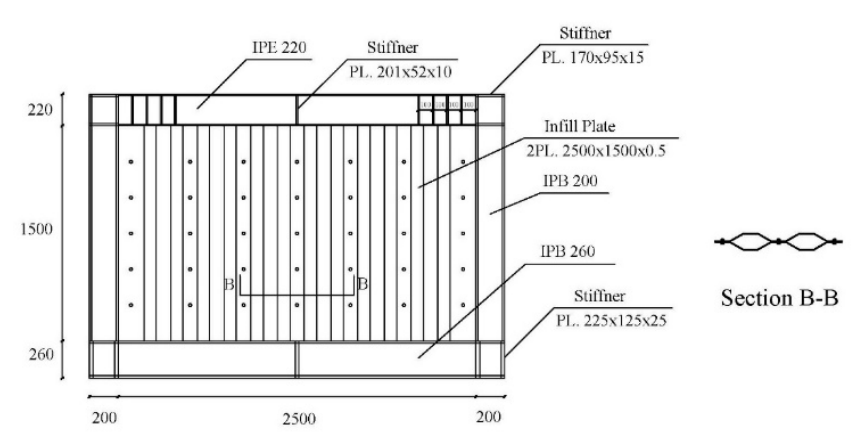

(b) Vertical DCSPSW

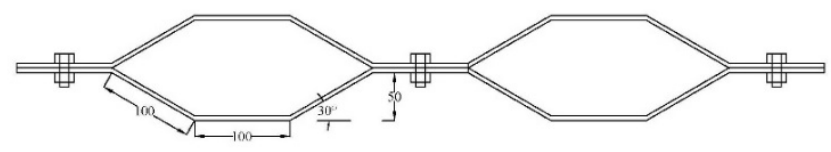

(c) Geometry of corrugated plates

Figure 2. DCSPSW specimens dimensions and member sizes (mm)

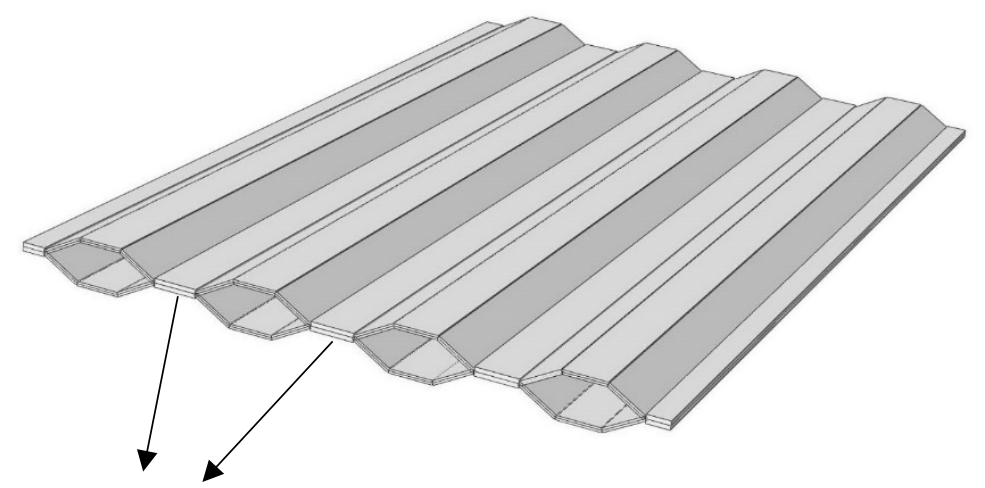

Directly connected

Figure 3. Finite element model of DCSPSW infill plates

Table 1. Material properties used in models

\begin{tabular}{cccc}
\hline Element & $\begin{array}{c}\text { Young’s modulus E } \\
(\mathrm{GPa})\end{array}$ & $\begin{array}{c}\text { Yield stress } \mathrm{F}_{\mathrm{y}} \\
(\mathrm{MPa})\end{array}$ & $\begin{array}{c}\text { Ultimate stress } \mathrm{F}_{\mathrm{u}} \\
(\mathrm{MPa})\end{array}$ \\
\hline Plate (ST12) & 200 & 262 & 360 \\
Frame (ST37) & 202 & 280 & 390 \\
\hline
\end{tabular}




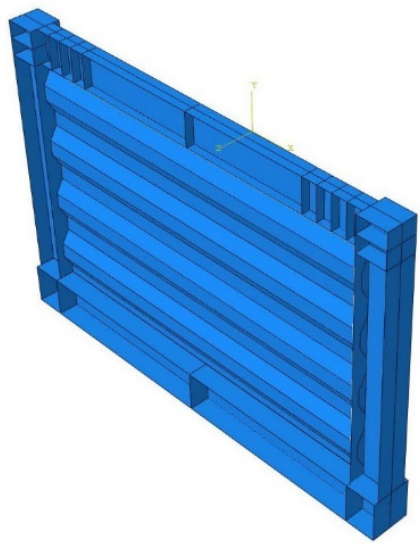

(a) Horizontal DCSPSW specimen

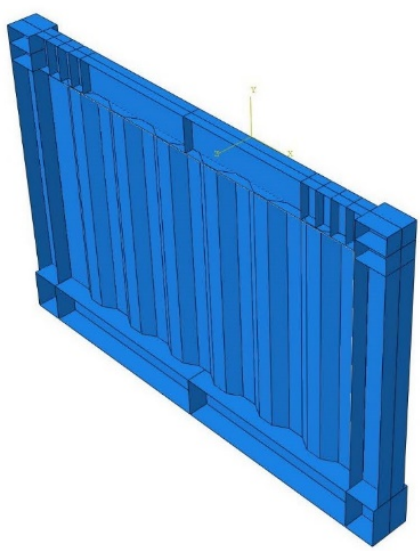

(b) Vertical DCSPSW specimen

Figure 4. Typical DCSPSW finite element models

As is practical in typical SPSW experiments [6,23], the effect of vertical load was neglected. The models were loaded horizontally at the top beam level using displacement control procedure according to the history shown in Figure 5. The loading protocol was created with combining the ATC-24 [24] and the AISC [2] requirements for cyclic loading as used in previous studies [23,25]. To develop the loading cycle amplitudes, specimen yield parameters are required. To this end, pushover analysis was carried out on the finite element model and yield displacement and force values were estimated.

Two displacement amplitudes of one third and two third of the estimated yield displacement were selected for elastic cycles. As yield drift was estimated to be $0.3 \%$, these amplitudes correspond to a drift of 0.1 and $0.2 \%$, respectively. ATC-24 [24] recommends that number of cycles with peak displacement less than yield displacement should be at least six. Thus, three cycles at each of these drift amplitudes were performed. Three cycles were performed at the estimated yield displacement according to ATC 24 [24] loading protocol. After that, peak displacements were increased by a ductility increment of one until achieving a ductility of three. Three cycles at each amplitude were applied. After this step, the number of cycles at each peak displacement was reduced from three to two. Peak displacements were increased by a ductility increment of one until reaching an estimated ductility of seven. Estimated ductility of seven coincided with $2.0 \%$ drift. After this point, peak displacements were increased by drift increments of $0.5 \%$ until reaching drift of $4.0 \%$, and increments of $1.0 \%$ until reaching drift of $6.0 \%$. Figure 5 shows the resulting loading history.

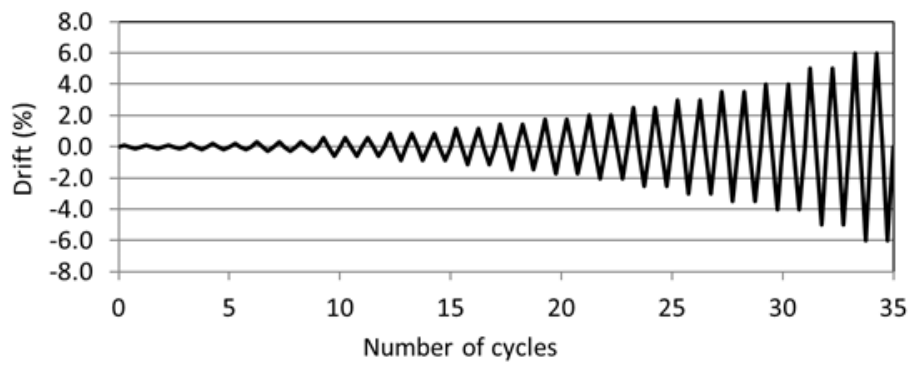

Figure 5. Cyclic loading protocol

\section{Validation}

In order to verify the accuracy of the finite element model, two sets of well-established experimental tests were considered for calibration. The first set is a flat SPSW tested by Vian et al. [25], and the other set is flat and single horizontal/vertical corrugated SPSWs tested by Emami et al. [6]. Hysteresis curves as well as model overall behaviour and failure modes under cyclic loading have been compared with those obtained from the experiments. Hysteresis curve of flat SPSW tested by Vian et al. and numerical results are shown in Figure 6. The experimental and numerical results of models tested by Emami et al. are illustrated in Figure 7 and tabulated in Table 2. Good agreement between the numerical and test results indicates the validity of the finite element modeling and its assumptions. 


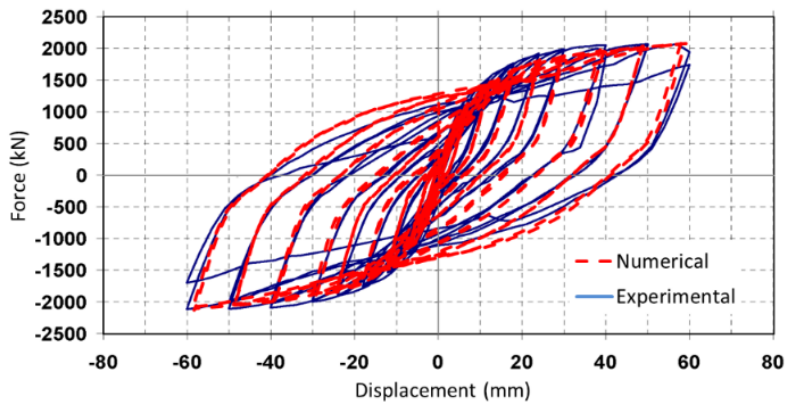

Figure 6. Comparison of experimental and analytical hysteresis curve for SPSW tested by Vian et al. [25]

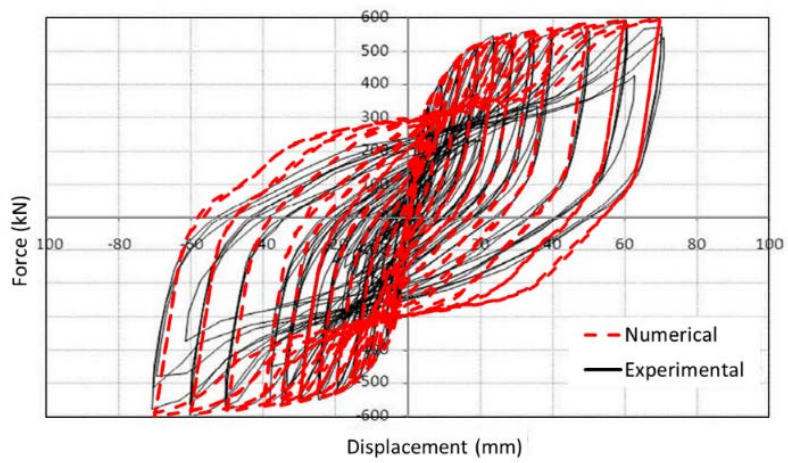

(a) Flat SPSW

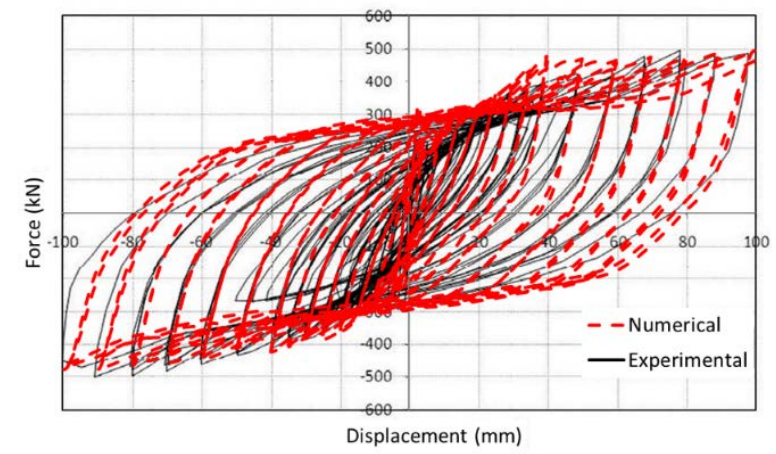

(b) Horizontal corrugated SPSW

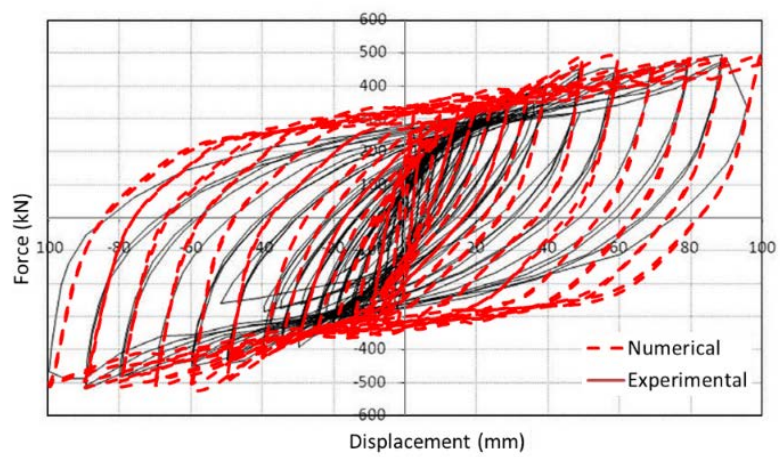

(c) Vertical corrugated SPSW

Figure 7. Comparison of experimental and analytical hysteresis curve for SPSWs tested by Emami et al. [6]

Table 2. Comparison of experimental and analytical results for initial stiffness and ultimate strength

\begin{tabular}{ccccccc}
\hline & \multicolumn{3}{c}{ Initial stiffness $(\mathrm{MN} / \mathrm{m})$} & \multicolumn{3}{c}{ Ultimate strength $(\mathrm{kN})$} \\
\cline { 2 - 7 } & Experimental & Numerical & Exp/Num & Experimental & Numerical & Exp/Num \\
\hline F-SPSW & 108 & 110.8 & 0.98 & 597 & 599.6 & 1.00 \\
H-CSPSW & 130 & 133.1 & 0.98 & 502 & 492.7 & 1.02 \\
V-CSPSW & 125 & 131.3 & 0.95 & 498 & 524.5 & 0.95 \\
\hline
\end{tabular}




\section{Parametric study}

To study the performance of doubly corrugated SPSWs, parametric studies were carried out on specimens whose details are illustrated in Figure 2. Parametric study includes the effect of corrugated plates orientation (horizontal or vertical), whether corrugated plates are connected to the columns or not, whether corrugated plates are connected together or not, corrugated plate thickness (t) and DCSPSW aspect ratio (Ar). The four different light gauge plate thicknesses and four different aspect ratios (length divided by height of the plate) considered are indicated in Table 3.

Table 3. DCSPSW parameters variation

\begin{tabular}{lllll}
\hline $\begin{array}{l}\text { Corrugated plates } \\
\text { orientation }\end{array}$ & $\begin{array}{l}\text { Infill plate to } \\
\text { columns connection }\end{array}$ & $\begin{array}{l}\text { Corrugated plate to } \\
\text { plate connection }\end{array}$ & $\begin{array}{l}\text { corrugated plate } \\
\text { thickness, t (mm) }\end{array}$ & $\begin{array}{l}\text { DCSPSW } \\
\text { aspect ratio, Ar }\end{array}$ \\
\hline $\begin{array}{l}\text { H (horizontal) \& } \\
\text { V (vertical) }\end{array}$ & Yes, No & Yes, No & $0.5,0.6,0.7,0.8$ & $1,1.67,2.33,3$ \\
\hline
\end{tabular}

\subsection{Effect of corrugated plate orientation}

Figure 8 presents the hysteresis curves for horizontal and vertical DCSPSWs and bare frame. Thickness of infill plate is $0.5 \mathrm{~mm}$ and aspect ratio is 1.67 and infill plates are connected to each other and fully restrained by beams and columns. According to ATC recommendation [26] ultimate displacement capacity of specimens should be limited to deformation associated with $80 \%$ of the ultimate strength on the descending branch of the modified backbone curve. Here, $20 \%$ strength loss occurs at the drift of 3\%. So hysteresis curves are reported up to 3\% drift. The initial stiffness, ultimate strength and energy dissipation capacity of specimens are tabulated in Table 4 . It is clear that DCSPSWs have much better performance in comparison to bare frame due to contributions of infill plates. Also note that, the horizontal and vertical DCSPSWs have comparable stiffness, strength, and energy dissipation capacity.

Figure 9 illustrates the maximum in-plane principal stress contour in horizontal and vertical DCSPSWs at 3\% drift. In DCSPSWs like single corrugated SPSWs, diagonal tension strips develop to resist lateral load. In addition, like single corrugated SPSWs the inclination angle of the tension field measured relative to the horizontal axis in horizontal DCSPSW specimen is less than that of vertical DCSPSW. Thus in H-DCSPSW, the columns and beams at the boundary play a role in forming tension field strips. On the contrary, in V-DCSPSW, as inclination angle of the tension strips is higher, development of diagonal tension field strips relies mostly on beams and less on columns.

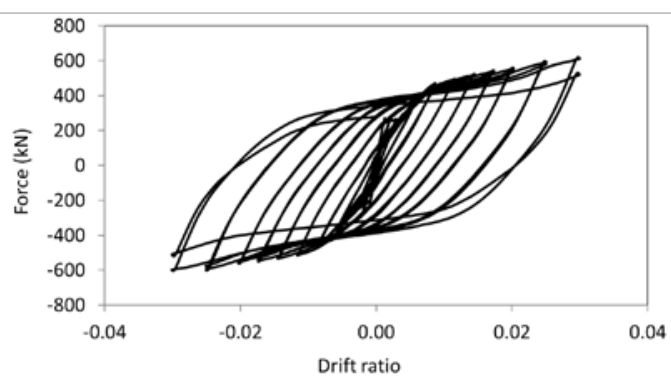

(a) H-DSPSW

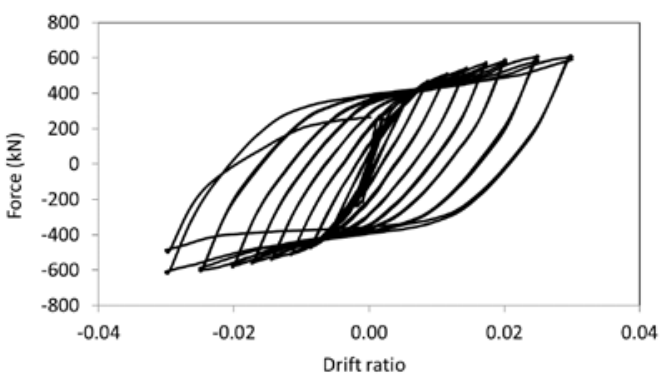

(b) V-DSPSW

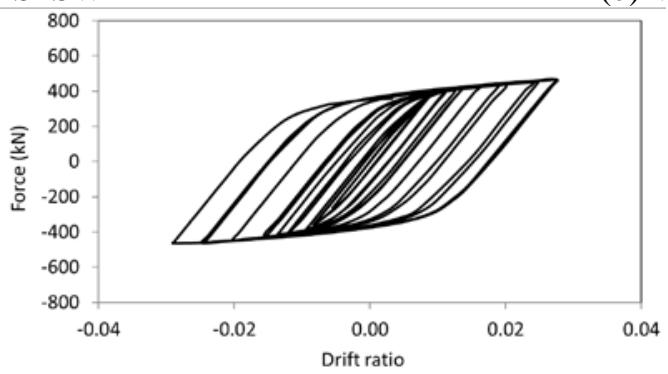

(c) Bare frame

Figure 8. Hysteresis curves of DCSPSWs with different configurations and bare frame

Table 4. Performance parameters of specimens

\begin{tabular}{cccc}
\hline Parameter & H-DCSPSW & V-DCSPSW & Bare Frame \\
\hline Initial stiffness $(\mathrm{MN} / \mathrm{m})$ & 145.6 & 145.3 & 27.7 \\
Ultimate strength $(\mathrm{kN})$ & 619.9 & 620.7 & 465.3 \\
Energy dissipation $(\mathrm{kN}-\mathrm{m})$ & 379.2 & 395.8 & 288.4 \\
\hline
\end{tabular}



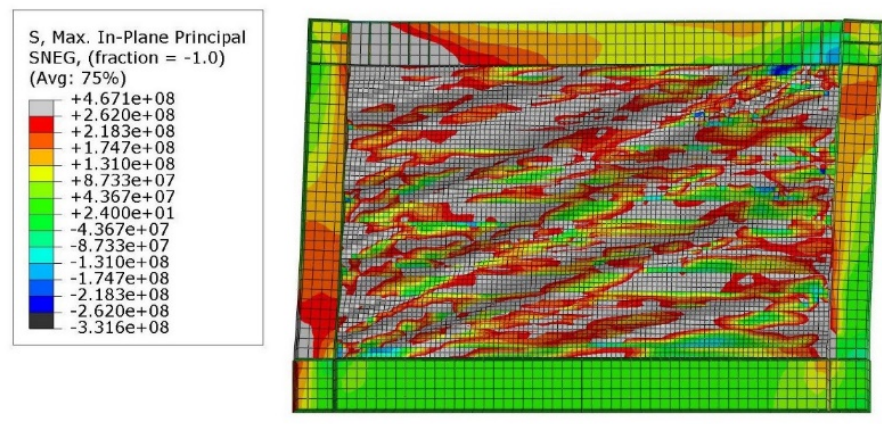

(a) H-DCSPSW
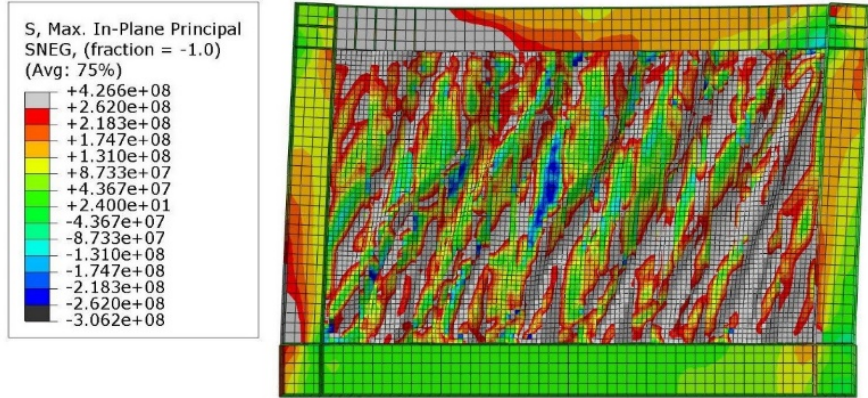

(b) V-DCSPSW

Figure 9. Maximum in-plane principal stress contours in DCSPSW $\left(\mathrm{N} / \mathrm{m}^{2}\right)$

\subsection{Effect of infill plate to column connections}

The diagonal tension strips impose high axial and flexural demands on the columns which may lead to premature failure of columns. For reducing column demands in SPSWs, several methods have been suggested by researchers including releasing the infill plate from columns and connecting it only to the beams [27,28]. In addition, connecting the corrugated infill plate specially the light gauge one to the surrounding frame members proved to be difficult due to thickness and geometry of the plate [5]. This could considerably increase the construction time. In beam-only-connected SPSWs, infill panel is only connected to the frame beams and connections between infill panel and columns are omitted.

The effects of infill plate connections to columns on the hysteretic performance of DCSPSW are investigated in this section. To make beam-only-connected DCSPSW in ABAQUS, it is just enough to remove the tie constraints between the columns and corrugated plates. The performances of DCSPSWs with both horizontal and vertical corrugation orientation with $\mathrm{t}=0.5 \mathrm{~mm}$ and $\mathrm{Ar}=1.67$ were evaluated. Infill plates were connected to each other. The hysteresis curves of beam-only-connected horizontal and vertical DCSPSWs are illustrated in Figure 10. The initial stiffness, ultimate strength and energy dissipation capacity of these specimens are presented in Table 5. By comparing Table 4 and Table 5, it can be seen that detaching columns from the infill plates reduces column demands at the expense of reduction in initial stiffness, ultimate strength and energy dissipation of DCSPSWs. In the case of horizontal DCSPSW, releasing columns from the infill plates decreased the initial stiffness from 145.6 $\mathrm{MN} / \mathrm{m}$ in the fully connected specimen to $28.3 \mathrm{MN} / \mathrm{m}$, showing $81 \%$ reduction. It reduced the ultimate strength and energy dissipation from 619.9 to $497.0 \mathrm{kN}$ and 379.2 to $308.5 \mathrm{kN}-\mathrm{m}$ showing $20 \%$ and $19 \%$ reductions, respectively. However, in the case of vertical DCSPSW releasing columns from the infill plates decreased the initial stiffness from $145.3 \mathrm{MN} / \mathrm{m}$ in the fully connected specimen to $113.3 \mathrm{MN} / \mathrm{m}$ showing only $22 \%$ reduction. It reduced the ultimate strength and energy dissipation from 620.7 to $587.5 \mathrm{kN}$ and 395.8 to $356.6 \mathrm{kN}$-m showing $5 \%$ and $10 \%$ reductions, respectively. It can be seen that the decrease in responses in beam-only-connected vertical DCSPSW is less than the decrease in responses in beam-only-connected horizontal DCSPSW and thus, the former has a better performance.

Figure 11 illustrates the maximum in-plane principal stress contour in beam-only-connected H-DCSPSW and V-DCSPSW at 3\% drift. In the previous section, it was shown that in H-DCSPSW, columns and beams play a role in forming diagonal tension field strips. Thus, by comparing Figure 9 (a) with Figure 11 (a) it can be seen that releasing columns from the infill plates in H-DCSPSW eliminates vertical boundary condition and thus eliminates most of the active tension field strips and just one strip from bottom left corner to upper right corner remains in beam-only-connected H-DCSPSW. Eliminating tension field strips corresponds to a decrease in infill plates' contributions and causes substantial decrease in initial stiffness, ultimate strength and energy dissipation. On the 
contrary, in V-DCSPSW, formation of tension field strips relies more on horizontal boundary conditions than vertical boundary conditions. Comparing Figure 9 (b) with Figure 11 (b) shows that releasing columns from the infill plates in V-DCSPSW eliminates just a few tension field strips and major part of infill plates' contributions remain. Therefore, beam-only-connected V-DCSPSW experiences less reduction in initial stiffness, ultimate strength and energy dissipation in comparison with beam-only-connected H-DCSPSW.

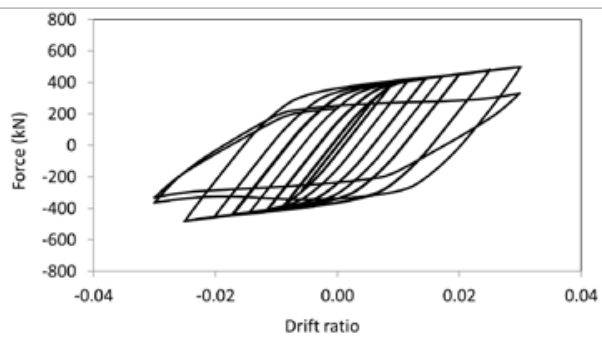

(a) Beam-only-connected H-DCSPSW

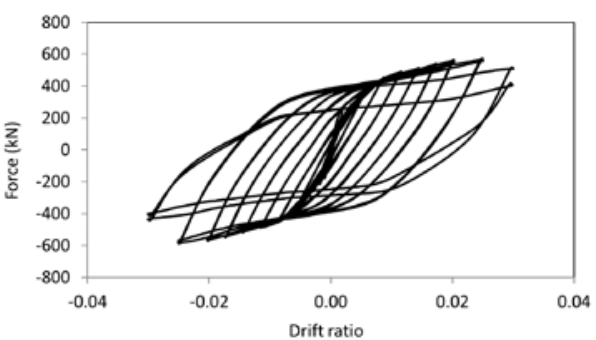

(b) Beam-only-connected V-DCSPSW

Figure 10. Hysteresis curves of DCSPSWs with beam-only-connected infill plates

Table 5. Performance parameters for beam only connected specimens

\begin{tabular}{ccc}
\hline Parameter & H-DCSPSW & V-DCSPSW \\
\hline Initial stiffness $(\mathrm{MN} / \mathrm{m})$ & 28.3 & 113.3 \\
Ultimate strength $(\mathrm{kN})$ & 497.0 & 587.5 \\
Energy dissipation $(\mathrm{kN}-\mathrm{m})$ & 308.5 & 356.6 \\
\hline
\end{tabular}
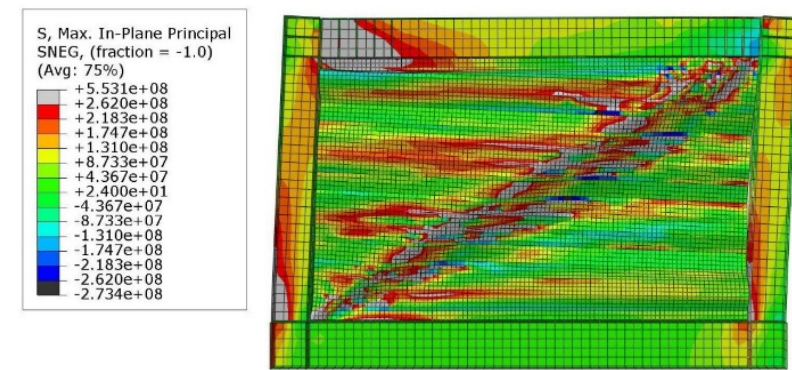

(a) Beam-only-connected H-DCSPSW
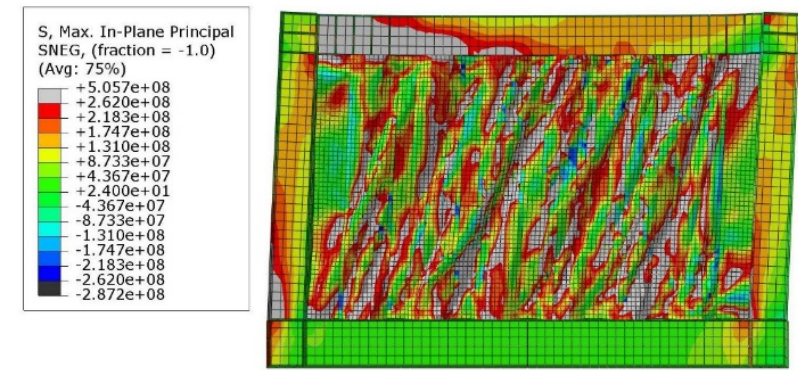

(b) Beam-only-connected V-DCSPSW

Figure 11. Maximum in-plane principal stress contours in beam only connected DCSPSW $\left(\mathrm{N} / \mathrm{m}^{2}\right)$

\subsection{Effect of plate to plate connections in DCSPSWs}

Figure 12 presents the hysteresis curves for horizontal and vertical DCSPSWs when the infill plates are detached from each other. In other words, bolts are omitted and corrugated plates are placed simply alongside each other with no connections. Thickness of infill plates is $0.5 \mathrm{~mm}$ and aspect ratio is 1.67 and infill plates are connected fully to the beams and columns. The initial stiffness, ultimate strength and energy dissipation capacity of DCSPSWs with separate infill plates are presented in Table 6. It can be seen that horizontal and vertical DCSPSWs with separate infill plates have relatively similar cyclic performance. In addition, comparing Table 4 and Table 6 reveals the effect of plate to plate connections on the response of DCSPSWs. In the case of H-DCSPSW, detaching plates from each other decreased the initial stiffness, ultimate strength and energy dissipation from $145.6 \mathrm{MN} / \mathrm{m}$, $619.9 \mathrm{kN}$ and $379.2 \mathrm{kN}-\mathrm{m}$ to $144.9 \mathrm{MN} / \mathrm{m}, 606.9 \mathrm{kN}$ and $371.3 \mathrm{kN}-\mathrm{m}$ showing $0.5 \%$, 2\% and 2\% reductions, 
respectively. In the case of V-DCSPSW detaching plates from each other decreased the initial stiffness, ultimate strength and energy dissipation from $145.3 \mathrm{MN} / \mathrm{m}, 620.7 \mathrm{kN}$ and $395.8 \mathrm{kN}-\mathrm{m}$ to $142.3 \mathrm{MN} / \mathrm{m}, 610.4 \mathrm{kN}$ and 363.9 $\mathrm{kN}-\mathrm{m}$ showing $2 \%, 2 \%$ and $8 \%$ reductions, respectively.

It can be seen that detaching plates from each other reduces the responses in DCSPSWs. This reduction is attributed to the fact that when DCSPSW infill plates are not connected to each other the out of plane stiffness of the section decreases and this causes a lower performance. However, this reduction is relatively small and DCSPSWs with detached infill plates have acceptable cyclic performance.

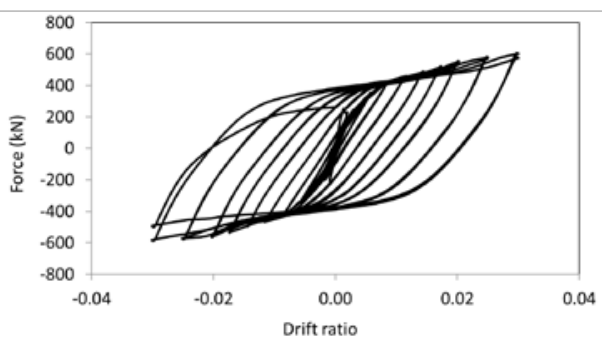

(a) H-DCSPSW

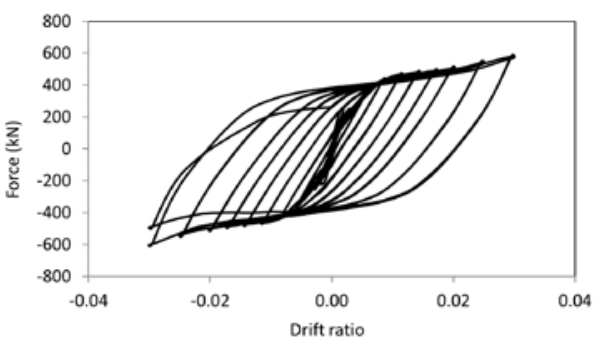

(b) V-DCSPSW

Figure 12. Hysteresis curves of DCSPSWs with detached infill plates

Table 6. Performance parameters for DCSPSWs with detached infill plates

\begin{tabular}{cll}
\hline Parameter & HDSPSW & VDSPSW \\
\hline Initial stiffness $(\mathrm{MN} / \mathrm{m})$ & 144.9 & 142.3 \\
Ultimate strength $(\mathrm{kN})$ & 606.9 & 610.4 \\
Energy dissipation $(\mathrm{kN}-\mathrm{m})$ & 371.3 & 363.9 \\
\hline
\end{tabular}

\subsection{Effect of thickness}

The effects of infill plate thickness on the cyclic behavior of DCSPSWs are investigated in this section. Performances of DCSPSWs with both horizontal and vertical orientations with $t=0.5,0.6,0.7$, and $0.8 \mathrm{~mm}$ were evaluated. Infill plates are connected fully to the beams and columns and also are connected to each other. Aspect ratio is 1.67. The cyclic behavior of horizontal and vertical DCSPSWs are illustrated in Figures 13 and 14, respectively. From these figures it can be seen that for both horizontal and vertical DCSPSWs increasing the infill plate thickness improves the cyclic behavior. However, it should be noted that this increase can also lead to larger demands on boundary frame members and this must be considered in the design.

The response of H-DCSPSW and V-DCSPSW as a function of infill plate thickness is given in Figures 15 (a) through (c). Initial stiffness, ultimate strength and energy dissipation increase proportionally with infill plate thickness for both. For H-DCSPSW increasing the infill plate thickness from $0.5 \mathrm{~mm}$ to $0.8 \mathrm{~mm}$ result in $43 \%$, $11 \%$ and $12 \%$ increase in the initial stiffness, ultimate strength and energy dissipation, respectively.

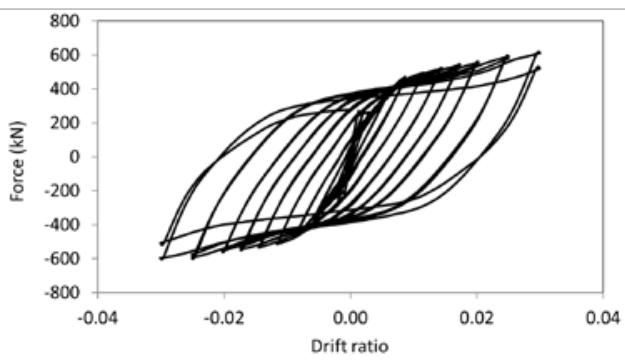

(a) $\mathrm{t}=0.5 \mathrm{~mm}$

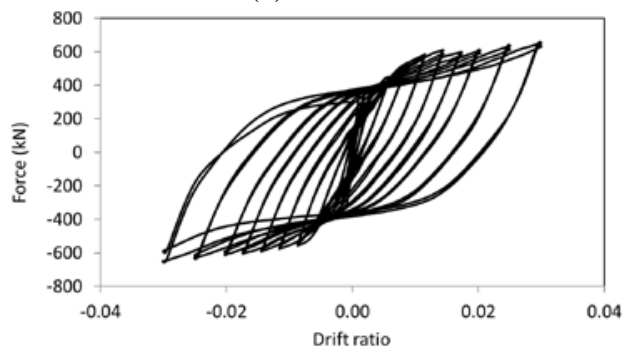

(c) $\mathrm{t}=0.7 \mathrm{~mm}$

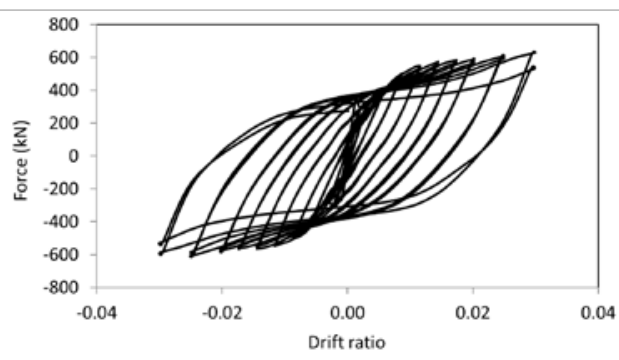

(b) $\mathrm{t}=0.6 \mathrm{~mm}$

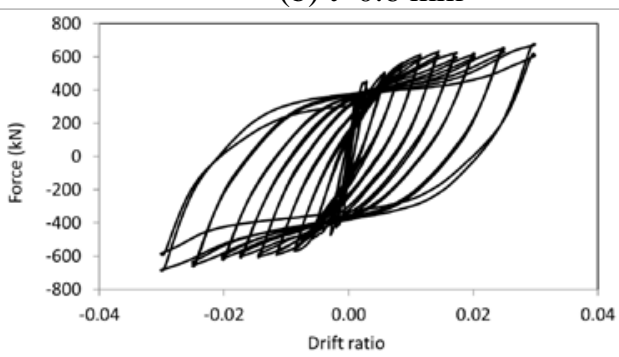

(d) $\mathrm{t}=0.8 \mathrm{~mm}$

Figure 13. Hysteresis curves of horizontal DCSPSW with different plate thicknesses 


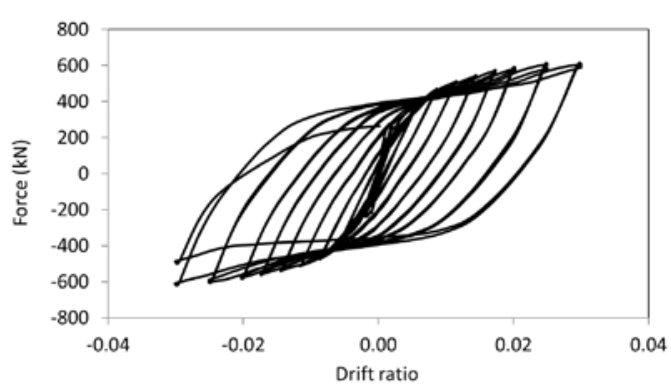

(a) $\mathrm{t}=0.5 \mathrm{~mm}$

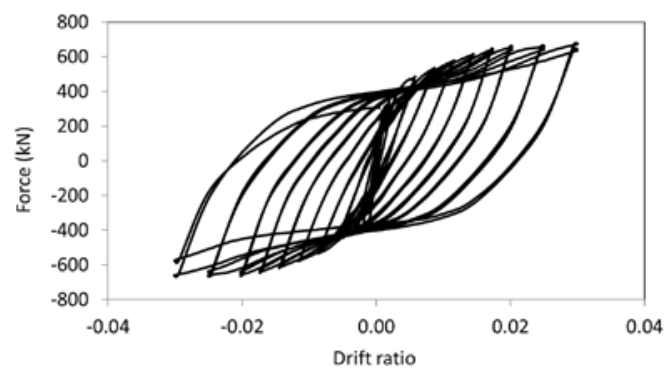

(c) $\mathrm{t}=0.7 \mathrm{~mm}$

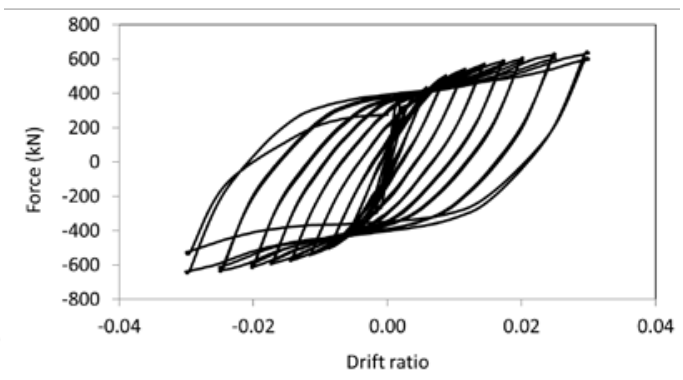

(b) $\mathrm{t}=0.6 \mathrm{~mm}$

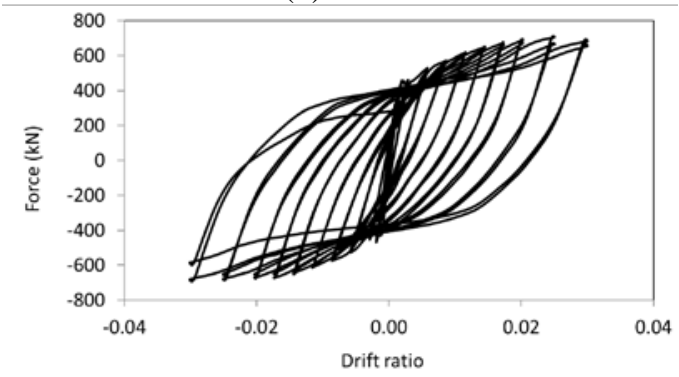

(d) $\mathrm{t}=0.8 \mathrm{~mm}$

Figure 14. Hysteresis curves of vertical DCSPSW with different plate thicknesses

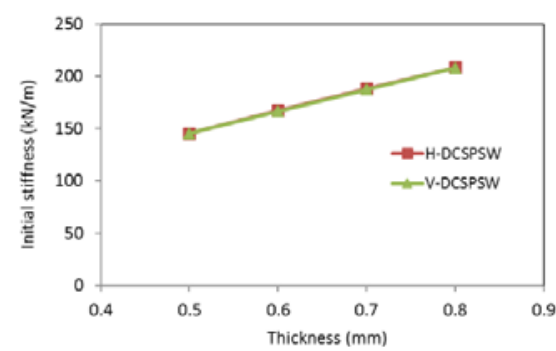

(a) Initial stiffness

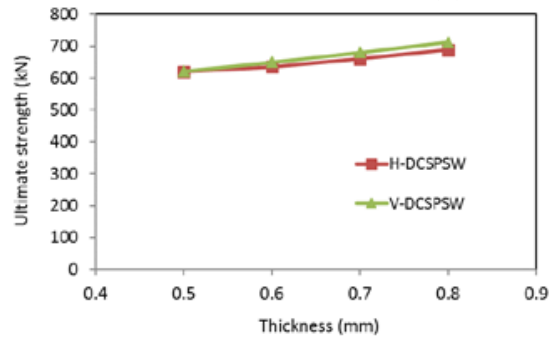

(b) Ultimate strength

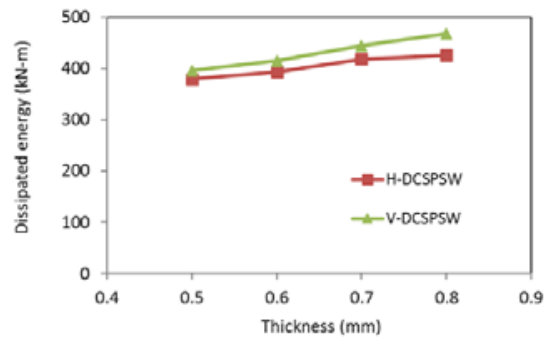

(c) Dissipated energy

Figure 15. The response of H-DCSPSW and V-DCSPSW as a function of infill plate thickness

\subsection{Effect of panel aspect ratio}

The effects of panel aspect ratio $\left(\mathrm{A}_{\mathrm{r}}\right)$ on the cyclic performance of DCSPSWs are investigated in this section. To study the different panel aspect ratios, the panel height was kept constant and equal to $1500 \mathrm{~mm}$ and length of the panel was varied. Panel aspect ratios are summarized in Table 7 and illustrated in Figure 16. The hysteresis curves of the horizontal DCSPSWs with $\mathrm{t}=0.5 \mathrm{~mm}$ are shown in Figure 17. Infill plates are connected fully to the beams and columns and are connected to each other. From Figure 17, it is found that increasing the panel aspect ratio from 1.00 to 3.00 can be effective in enhancing the cyclic performance of the DCSPSWs. In fact, increasing of the panel aspect ratio increases the number of tension field strips forming in the panel and this results in greater initial stiffness, ultimate strength and dissipated energy.

Table 7. Panel aspect ratios

\begin{tabular}{ccccc}
\hline H, Height of panel $(\mathrm{mm})$ & 1500 & 1500 & 1500 & 1500 \\
\hline L, Length of panel (mm) & 1500 & 2500 & 3500 & 4500 \\
\hline $\mathrm{A}_{\mathrm{r}}$, panel aspect ratio & 1.00 & 1.67 & 2.33 & 3.00 \\
\hline
\end{tabular}




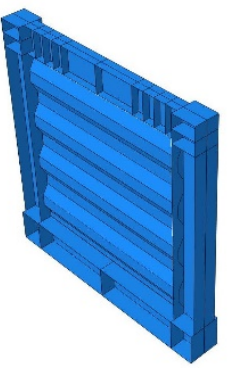

(a) $A_{r}=1.00$

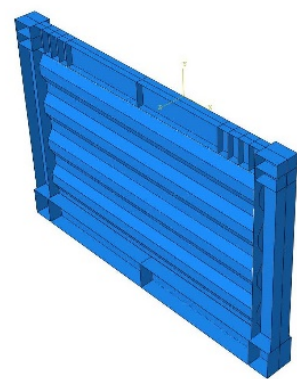

(b) $\mathrm{A}_{\mathrm{r}}=1.67$

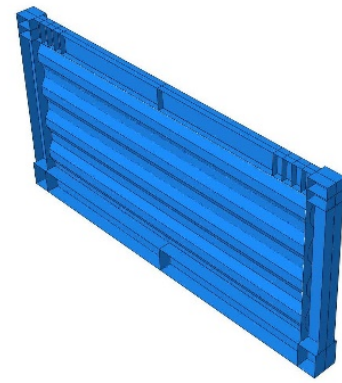

(c) $\mathrm{A}_{\mathrm{r}}=2.33$

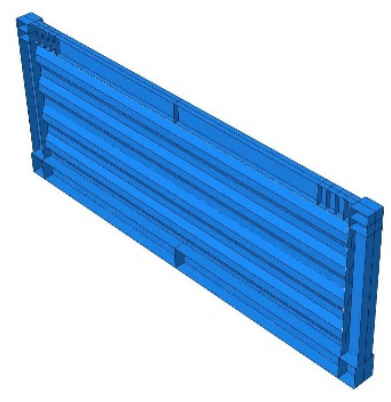

(d) $A_{r}=3.00$

Figure 16. Different panel aspect ratios

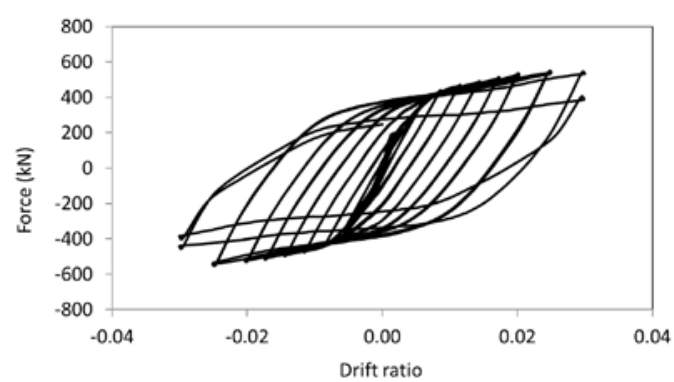

(a) $\mathrm{A}_{\mathrm{r}}=1.00$

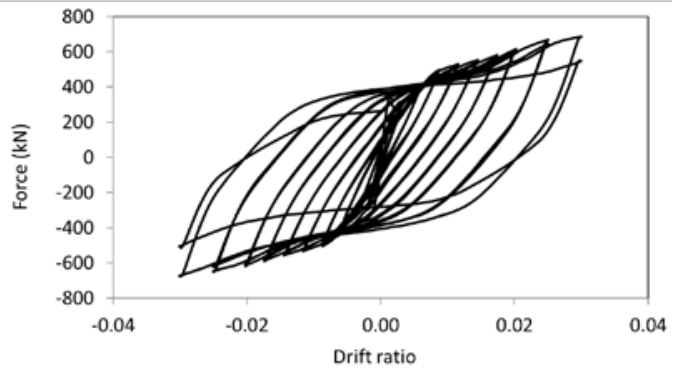

(c) $\mathrm{A}_{\mathrm{r}}=2.33$

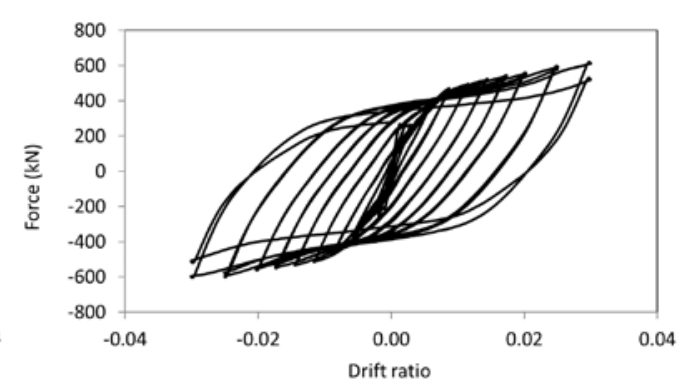

(b) $\mathrm{A}_{\mathrm{r}}=1.67$

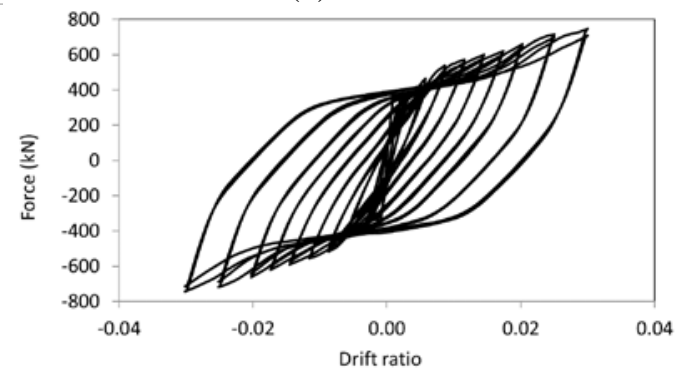

(d) $A_{r}=3.00$

Figure 17. Hysteresis curves for beam-only-connected horizontal DCSPSW with varying panel aspect ratios

The responses of horizontal DCSPSWs as a function of panel aspect ratio are tabulated in Table 8 . It can be seen that, initial stiffness, ultimate strength and energy dissipation increase with infill panel aspect ratio. Increasing the panel aspect ratio from 1.0 to 3.0 increase the initial stiffness, ultimate strength and energy dissipation from 100.2 MN/m, 553.7 kN and 357.3 kN-m to 235.3 MN/m, $753.6 \mathrm{kN}$ and $412.4 \mathrm{kN}-\mathrm{m}$ showing $135 \%$, 36\% and $15 \%$ increase, respectively. So it is better to use DCSPSWs in wider bays of a building.

Table 8. Performance parameters of horizontal DCSPSWs as a function of panel aspect ratio

\begin{tabular}{cccc}
\hline Ar & $\begin{array}{c}\text { Initial stiffness } \\
(\mathrm{MN} / \mathrm{m})\end{array}$ & $\begin{array}{c}\text { Ultimate strength } \\
(\mathrm{kN})\end{array}$ & $\begin{array}{c}\text { Energy dissipation } \\
(\mathrm{kN}-\mathrm{m})\end{array}$ \\
\hline 1.00 & 100.2 & 553.7 & 357.3 \\
1.67 & 145.6 & 619.9 & 379.2 \\
2.33 & 190.5 & 687.1 & 390.4 \\
3.00 & 235.3 & 753.6 & 412.4 \\
\hline
\end{tabular}

\section{Initial stiffness and ultimate strength of DCSPSWs}

Ultimate shear strength of DCSPSWs can be estimated via Equation (1):

$$
F_{s u}=F_{f u}+F_{p t}
$$

where $F_{s u}$ is the ultimate shear strength of the steel plate shear wall, $F_{f u}$ is strength of bare frame and $F_{p t}$ is strength of plate. $F_{f u}$ is given by Equation (2): 


$$
F_{f u}=4 M_{p} / h_{s}
$$

where $M_{p}$ is the smallest of the plastic moment capacity of the beam and columns and $h_{s}$ is height of the specimen. $F_{p t}$ is given by Equation (3) [13]:

$$
F_{p t}=L t\left(\tau_{c r . i n}^{e}+0.5 \sigma_{t y} \sin 2 \theta\right)
$$

in which $L$ and $t$ are length and thickness of the infill plate, respectively. $\tau_{c r . i n}^{e}$ is the plate interactive shear buckling stress and $\sigma_{t y}$ is the yield stress of tension field calculated via Von-Mises criterion. . $\tau_{c r . i n}^{e}$ is obtained as follows [13,29]:

$$
\left(\frac{1}{\tau_{c r . i n}^{e}}\right)^{2}=\left(\frac{1}{\tau_{c r . L}^{e}}\right)^{2}+\left(\frac{1}{\tau_{c r . G}^{e}}\right)^{2}+\left(\frac{1}{\tau_{y}}\right)^{2}
$$

in which $\tau_{y}$ is yielding shear stress, $\tau_{c r . L}^{e}$ and $\tau_{c r . G}^{e}$ are local and global shear buckling stresses which can be calculated from Equations (5) and (6):

$$
\begin{aligned}
\tau_{c r . L}^{e} & =\left[5.34+4\left(\frac{a}{h}\right)^{2}\right] \frac{\pi^{2} E}{12\left(1-\vartheta^{2}\right)}\left(\frac{t}{a}\right)^{2} \\
\tau_{c r . G}^{e} & =\frac{36 \varphi E}{\left[12\left(1-\vartheta^{2}\right)\right]^{0.25}}\left[\frac{\left(\frac{d}{t}\right)^{2}+1}{6 \gamma}\right]^{0.75}\left(\frac{t}{h}\right)^{2}
\end{aligned}
$$

$E$ is Young's modulus of elasticity and $\vartheta$ is Poisson ratio; $h$ is panel height; $\varphi$ is boundary condition factor varying from 1.0 to 1.9 and assumed to be 1.0 due to simple support condition [13]. $\gamma$ is a factor which accounts for corrugation geometry and obtained using Equation (7):

$$
\gamma=\frac{a+b}{a+c}
$$

$a, b, c$ and $d$ are parameters of corrugated panel geometry which are illustrated in Figure 18.

$\sigma_{t y}$ is the yield tension field stress calculated using Equation (8) [13]:

$$
\sigma_{t y}^{2}+\left(3 \tau_{c r . i n}^{e} \sin 2 \theta\right) \sigma_{t y}+\left(3 \tau_{c r . i n}^{e}{ }^{2}-\sigma_{y}^{2}\right)=0
$$

where $\theta$ is tension field inclination angle measured relative to the horizontal axis and assumed to be 30 and 60 degree for horizontal and vertical specimens [6]. $\sigma_{y}$ is yield stress of steel plate.

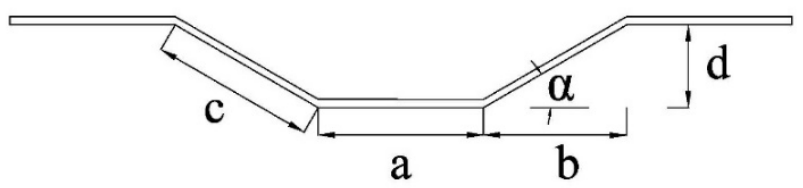

Figure 18. Parameters of corrugated panel geometry

To estimate the equivalent thickness of DCSPSWs, a single panel corrugated SPSW with the same infill plate shape and twice the thickness was modeled and their initial stiffness and ultimate strength were calculated (Figure 19). The boundary elements (beams and columns) were kept the same. Initial stiffness and ultimate strength of DCSPSW with each plate thickness of $t$ were compared with those of single corrugated SPSW with infill plate thickness of 2t. Thus, initial stiffness ratio was defined as the ratio of initial stiffness of double panel SPSW with each plate thickness of $t$ with respect to that of single panel SPSW with infill plate thickness of 2t. Ultimate strength ratio was defined in a similar way.

Figure 20 presents the initial stiffness and ultimate strength ratio as a function of $t$ for both horizontal and vertical corrugated SPSWs. Panel aspect ratio is 1.67. It can be seen that the initial stiffness ratio is a bit larger than one for considered thicknesses showing that initial stiffness of double corrugated SPSW is a bit larger than initial stiffness of single corrugated SPSW with infill plate thickness of 2t. This can be attributed to the fact that 
double corrugated SPSW has larger out of plane stiffness in comparison to single corrugated SPSW with thickness of 2t. Ultimate strength ratio is approximately equal to one which means that ultimate strength of double panel SPSW is approximately equal to ultimate strength of single panel SPSW with infill plate thickness of 2t.
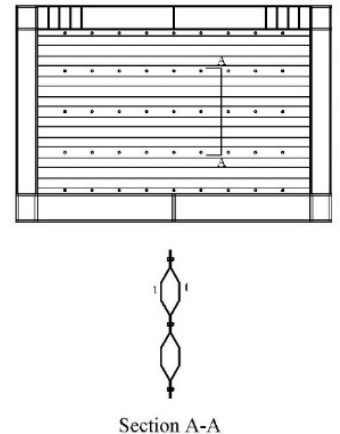
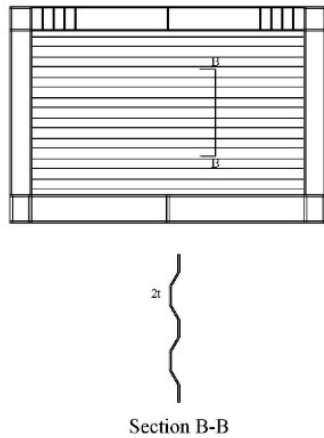

Figure 19. Comparison of double corrugated SPSW with plate thicknesses of $t$ with single corrugated SPSW with infill plate thickness of $2 \mathrm{t}$

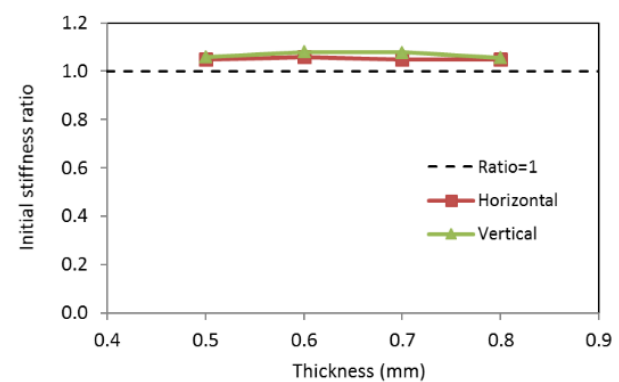

(a) Initial stiffness ratio

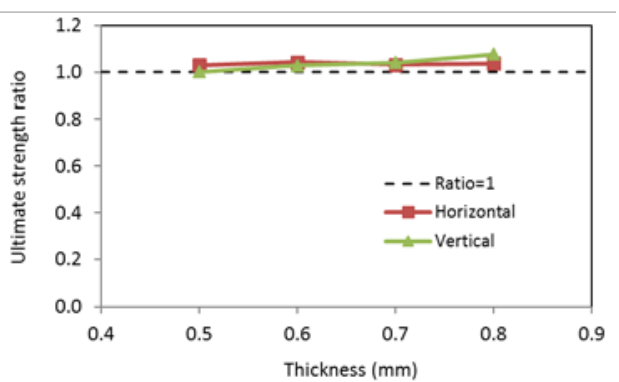

(b) Ultimate strength ratio

Figure 20. Initial stiffness and ultimate strength ratio as a function of $t$

Initial stiffness and ultimate strength ratio as a function of panel aspect ratio (Ar) for horizontal corrugated SPSWs are tabulated in Table 9. Each infill plate thickness in double panel SPSWs is $0.5 \mathrm{~mm}$ and infill plate thickness in single panel SPSWs is $1.0 \mathrm{~mm}$. It can be seen that the initial stiffness and ultimate strength of DCSPSW is greater than those of single corrugated SPSW. However, the difference is less than $6 \%$ and $3 \%$ for initial stiffness and ultimate strength ratio, respectively. Thus, it can be concluded that for different thicknesses and aspect ratios using an equivalent thickness of 2t in Equations (3) to (8) for DCSPSW is valid and conservative.

To elaborate, ultimate shear strength of horizontal and vertical DCSPSWs with each infill plate thickness of 0.5 $\mathrm{mm}$ and panel aspect ratio of 1.67 were estimated through analytical method using Equations (1) to (8) and compared with finite element (FE) results (Table 10). Equivalent thickness of the infill plate was assumed to be $1.0 \mathrm{~mm}$. Table 10 indicates that analytical equations can predict the ultimate strength of DCSPSWs with less than $4 \%$ error.

Table 9. Initial stiffness and ultimate strength ratio as a function of panel aspect ratio

\begin{tabular}{ccccccc}
\hline \multirow{2}{*}{$\mathrm{A}_{\mathrm{r}}$} & \multicolumn{2}{c}{$\begin{array}{c}\text { DCSPSW } \\
\text { (each infill plate thickness }=\mathrm{t})\end{array}$} & $\begin{array}{c}\text { Single corrugated SPSW } \\
\text { (infill plate thickness }=2 \mathrm{t})\end{array}$ & \multicolumn{2}{c}{ ratios } \\
\cline { 2 - 7 } & $\begin{array}{c}\text { Initial stiffness } \\
(\mathrm{MN} / \mathrm{m})\end{array}$ & $\begin{array}{c}\text { Ultimate strength } \\
(\mathrm{kN})\end{array}$ & $\begin{array}{c}\text { Initial stiffness } \\
(\mathrm{MN} / \mathrm{m})\end{array}$ & $\begin{array}{c}\text { Ultimate strength } \\
(\mathrm{kN})\end{array}$ & $\begin{array}{c}\text { Initial stiffness } \\
\text { ratio }\end{array}$ & $\begin{array}{c}\text { Ultimate } \\
\text { strength ratio }\end{array}$ \\
\hline 1.00 & 100.2 & 553.7 & 95.4 & 537.6 & 1.05 & 1.03 \\
1.67 & 145.6 & 619.9 & 137.4 & 601.9 & 1.06 & 1.03 \\
2.33 & 190.5 & 687.1 & 181.4 & 673.6 & 1.05 & 1.02 \\
3.00 & 235.3 & 753.6 & 224.1 & 731.7 & 1.05 & 1.03 \\
\hline
\end{tabular}

Table 10. Comparison of ultimate strength calculated with analytical method and FE analysis

\begin{tabular}{cccc}
\hline Specimen & $\begin{array}{c}\text { Strength by analytical method } \\
(\mathrm{kN})\end{array}$ & $\begin{array}{c}\text { Strength by FE analysis } \\
(\mathrm{kN})\end{array}$ & $\begin{array}{c}\text { Error } \\
(\%)\end{array}$ \\
\hline Horizontal & 642.2 & 619.9 & 3.5 \\
Vertical & 642.2 & 620.7 & 3.4 \\
\hline
\end{tabular}




\section{Conclusions}

Cyclic performance of double corrugated steel plate shear walls (DCSPSWs) was investigated in this study. Several finite element models were developed and analysed for parametric studies. Infill plate orientation, connection of infill plate to columns, connection of infill plates together, infill plate thickness and panel aspect ratio were considered as the main parameters in this performance evaluation. Responses of interest are forcedeformation relationship, initial stiffness, ultimate strength and energy dissipation capacity. The following conclusions can be drawn based on this study:

1) Horizontal and vertical DCSPSWs fully restrained by beams and columns, have comparable stiffness, strength and energy dissipation capacity.

2) Releasing columns from infill plates reduces column demands at the expense of reduction in seismic responses of DCSPSWs. However, decrease in responses of beam-only-connected V-DCSPSWs is meaningfully less than the decrease in responses of beam-only-connected H-DCSPSWs and thus beam-only-connected VDCSPSWs have a better performance.

3) Detaching corrugated plates from each other in DCSPSWs cause negligible reduction in responses in comparison with bolted plates. In other words, DCSPSWs with detached infill plates have acceptable cyclic performance.

4) By increasing the corrugated plate thickness, initial stiffness, ultimate strength and energy dissipation increase proportionally for both H-DCSPSW and V-DCSPSW.

5) Increasing panel aspect ratio can be effective in enhancing the cyclic performance of the DCSPSWs. In other words, it is better to use DCSPSWs in wider bays of a building.

6) The initial stiffness and ultimate strength of DCSPSWs can be estimated by using an equivalent thickness of $2 \mathrm{t}$ in the given equations.

7) Analytical equations can predict the ultimate strength of DCSPSWs with less than $4 \%$ error.

\section{References}

[1] Sabelli R, Bruneau M. Design guide 20: steel plate shear walls. AISC, Chicago, IL. 2007.

[2] AISC. Seismic provisions for structural steel buildings. American Institute of Steel Construction. ANSI/AISC 341-16, Chicago, IL. 2016.

[3] Purba R, Bruneau M. Finite-element investigation and design recommendations for perforated steel plate shear walls. Journal of Structural Engineering. 2009;135(11):1367-1376.

[4] Zirakian T, Zhang J. Structural performance of unstiffened low yield point steel plate shear walls. Journal of Constructional Steel Research. 2015;112:40-53.

[5] Berman J, Bruneau M. Experimental investigation of light-gauge steel plate shear walls. Journal of Structural Engineering. 2005;131(2):259-267.

[6] Emami F, Mofid M, Vafai A. Experimental study on cyclic behavior of trapezoidally corrugated steel shear walls. Engineering Structures. 2013;48(6):750-762.

[7] Emami F, Mofid M. On the hysteresis behavior of trapezoidally corrugated steel shear walls. The Structural Design of Tall and Special Buildings. 2014;23(2):94-104.

[8] Farzampour A, Laman JA. Behavior prediction of corrugated steel plate shear walls with openings. Journal of Constructional Steel Research. 2015;114:258-268.

[9] Bahrebar M, Zaman Kabir M, Zirakian T, Hajsadeghi M, Lim J. Structural performance assessment of trapezoidally corrugated and centrally-perforated steel plate shear walls. Journal of Constructional Steel Research. 2016;122:584-594.

[10] Cao Q, Huang J. Experimental study and numerical simulation of corrugated steel plate shear walls subjected to cyclic loads. Thin-Walled Structures. 2018;127:306-317.

[11] Tong JZ, Guo YL, Zuo JQ. Elastic buckling and load-resistant behaviors of double-corrugated-plate shear walls under pure in-plane shear loads. Thin-Walled Structures. 2018;130:593-612.

[12] Dou C, Pi Y, Gao W. Shear resistance and post-buckling behavior of corrugated panels in steel plate shear walls. Thin-Walled Structures. 2018;131:816-826.

[13] Farzampour A, Mansouri I, Lee C, Sim H, Hu JW. Analysis and design recommendations for corrugated steel plate shear walls with a reduced beam section. Thin-Walled Structures. 2018;132:658-666.

[14] Bahrebar M, Lim JBP, Clifton GC, Zirakian T, Shahmohammadi A, Hajsadeghi M. Perforated steel plate shear walls with curved corrugated webs under cyclic loading. Structures. 2020;24:600-609.

[15] Fang J, Bao W, Ren F, Guan T, Xue G, Jiang J. Experimental study of hysteretic behavior of semi-rigid frame with a corrugated plate. Journal of Construction Steel Research. 2020;174:106289. 
[16] Bahrebar M, Lim JBP, Clifton GC, Zirakian T, Shahmohammadi A, Hajsadeghi M. Response assessment and prediction of low yield point steel plate shear wall with curved corrugated web plates and reduced beam sections. Structures. 2020;28:1729-1745.

[17] ABAQUS 6.14.3. ABAQUS 6.14.3 Documentation. Hibbitt, Karlson, Sorenson, Inc. 2015.

[18] Driver RG, Kulak GL, Kennedy DJL, Elwi AE. Seismic behavior of steel plate shear walls. Structural Engineering Report No. 215. Department of Civil Engineering, University of Alberta. Edmonton, Alberta, Canada. 1997.

[19] DIN 1623. 1629 International standard of germany. 1983.

[20] Hosseinzadeh L, Emami F, Mofid M. Experimental investigation on the behavior of corrugated steel shear wall subjected to the different angle of trapezoidal plate. The Structural Design of Tall and Special Buildings. 2017;26 (17):1-17.

[21] Jahanpour A, Jönsson J, Moharrami H. Seismic behavior of semi-supported steel shear walls. Journal of Construction Steel Research. 2012;74:118-133.

[22] Yu HL, Jeong DY. Application of stress triaxiality dependent fracture criterion in the finite element analysis of unnotched charpy specimens. Theoretical and Applied Fracture Mechanics. 2010;54 (1):54-62.

[23] Vian D, Bruneau M, Tsai K, Lin Y. Special perforated steel plate shear walls with reduced beam section anchor beams. I: Experimental investigation. Journal of Structural Engineering. 2009;135(3):211-220.

[24] ATC. Guidelines for cyclic seismic testing of components of steel structures. Applied Technology Council. Report No. 24. Redwood City. Ca. 1992.

[25] Vian D, Bruneau M, Purba R. Special perforated steel plate shear walls with reduced beam section anchor beams. II: Analysis and design recommendations. Journal of Structural Engineering. 2009;135(3):221-228.

[26] ATC. Modeling and acceptance criteria for seismic design and analysis of tall buildings. Applied Technology Council. Report No. 72. Redwood City. Ca. 2010.

[27] Choi I, Park H. Steel plate shear walls with various infill plate designs. Journal of Structural Engineering. 2009;135(7):785-796.

[28] Guo L, Rong Q, Ma X, Zhang S. Behavior of steel plate shear wall connected to frame beams only. International Journal of Steel Structures. 2011;11(4):467-479.

[29] Yi J, Gil H, Youm K, Lee H. Interactive shear buckling corrugated steel webs. Engineering Structures. 2008;30(6):1659-1666.

(C) 2021 by the author(s). This work is licensed under a Creative Commons Attribution 4.0 International License (http://creativecommons.org/licenses/by/4.0/). Authors retain copyright of their work, with first publication rights granted to Tech Reviews Ltd. 